\title{
TRÊS ESPÉCIES NOVAS DE NEOMUSCINA TOWNSEND (DIPTERA, MUSCIDAE, AZELINAE, REINWARDTIINI) DO BRASIL
}

\author{
Sonia Maria Lopes ${ }^{1}$ \\ Andréa Khouri ${ }^{1}$
}

\begin{abstract}
THrei new species of Neomuscina TOWnSEnd) (Diptera, Muscidae, AZEIINAE, REINWARDTINI) FROM BRAZII. Three new brazilian species are described: Neomuscina douradensis, sp.n. (Mato Grosso do Sul, Dourados), N. mimosa, sp.n. (Goiás. Golanésia) and N. paramediana, sp.n. (Goiás. Goianésia) are presented. KEY WORDS. Diptera, Muscidae, Neomuscina
\end{abstract}

Acrescentar-se ao gênero Neomuscina Townsend, 1919, três espécies novas, às 30 catalogadas por PONT (1972) é a proposta do presente trabalho.

Neomuscina é um gênero essencialmente neotropical, com somente uma espécie assinalada para a África, citada por SNYDER (1949), que suspeita que essa espécie ( $N$. transporta Snyder, 1949), tenha sido levada por avião em importação de material trazido da América do Sul. Menciona ele, ter essa espécie sido procurada durante 16 meses no Oeste da África, incluindo vizinhanças do aeroporto de St. Accra, e não ter sido coletada. Pont (1972) transcreve uma carta de Sabrosky para EMDEN (1951), onde diz ter sido o material coletado em avião, após sua limpeza em St. Accra.

\section{Neomuscina douradensis, sp.n.}

Figs $1-3,5,8$

Coloração geral amarelo. Antenas, palpos, pleuras, pós-pronoto e pernas amarelas. Cílios frontais, genais, ocelares castanho escuros. Tórax dorsalmente, visto à certa luz, polinoso esbranquiçado com uma listra central. Abdome castanho amarelado escurecendo para o ápice. Caliptras amareladas. Balacins amarelos na base, com extremidade castanho amarelada. Asas hialinas com manchas castanhas na costal e nas transversais.

Macho. Comprimento total $6 \mathrm{~mm}$.

Cabeça. Olhos nus, unidos com as facetas ântero internas alargadas sendo a largura ao nível do ocelo anterior subigual à largura do terceiro artículo antenal. Cerdas frontais em número de 10 pares, o segundo par mais forte, e a partir do sexto as cerdas são reclinadas e ciliformes. Cerdas ocelares proclinadas, seme-

1) Departamento de Entomologia. Museu Nacional, Universidade Federal do Rio de Janeiro, 20940-(040) Rio de Janeiro, Rio de Janeiro, Brasil. 
lhantes ao primeiro par de cerdas frontais no comprimento. Cerdas verticais internas e externas divergentes entre si. Antenas longas quase atingindo o epístoma e inseridas quase ao nível da metade dos olhos. Arista plumosa. Carena parafacial com cílios curtos e claros. Parafaciália subigual à espessura do terceiro artículo antenal no ápice. Vibrissas robustas e inseridas na margem oral. Epístoma não saliente. Palpos falciformes.
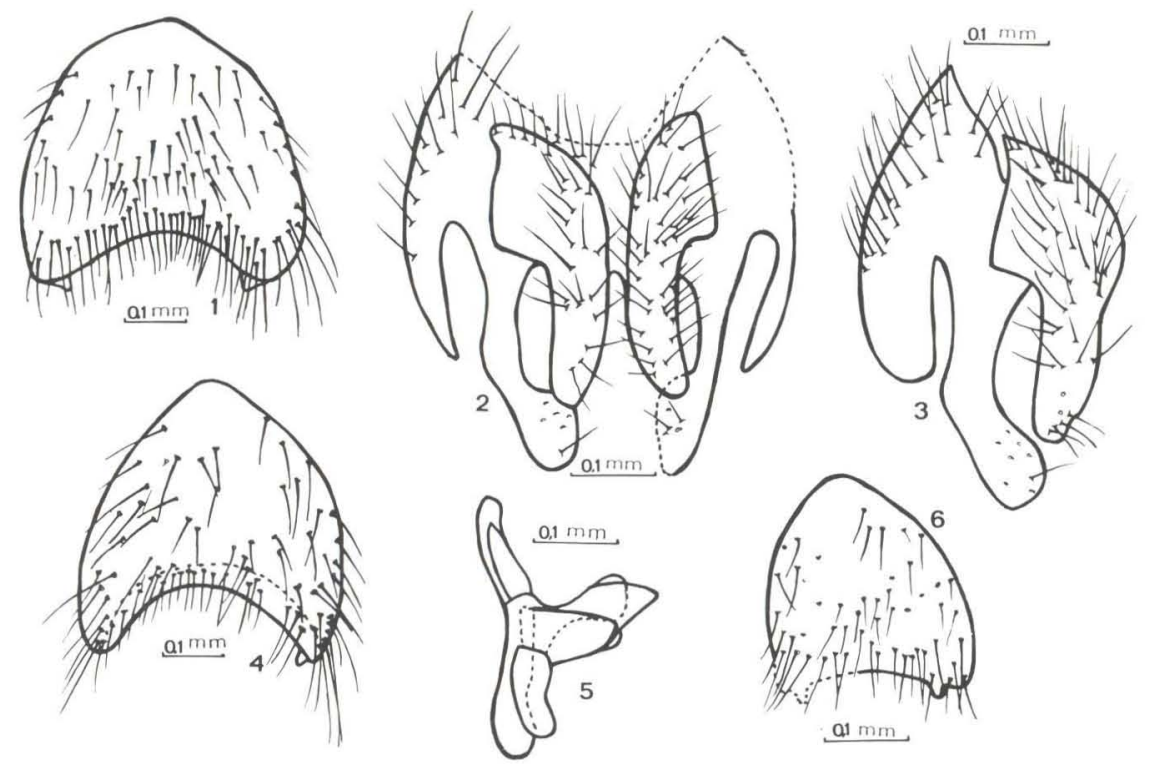

Figs 1-6. (1-3) Neomuscina douradensis, sp.n., (1) quinto esternito do macho; (2) placa cercal, vista dorsal; (3) placa cercal, vista lateral; (4) N. mimosa, sp.n., quinto esternito do macho; (5) N. douradensis, sp.n., pênis e anexos, vista lateral; (6) N. paramediana, sp.n., quinto esternito do macho.

Tórax. Cerdas dorsocentrais $2+4$; acrosticais $0+1$; três cerdas umerais; uma pós-pronotal; uma pré-sutural; uma pré-alar; duas supra-alares; duas póssupra-alares; duas notopleurais e duas intra-alares. Anepisterno com nove cerdas sendo duas ciliformes. Cerdas catepisternais 1:2. Escutelo com um par de cerdas discais, um par de cerdas pré-apicais e um de cerdas apicais fortes. Cílios escutelares penetrando lateralmente sem atingir a superfície ventral. Espiráculo torácico com abertura reniforme. Caliptra torácica glossiforme medindo cerca de 1,5 vezes a alar. Asas com $\mathrm{M}_{1+2}$ acentuadamente curva para o ápice. $\mathrm{R}_{1}$ na face ventral no nódulo com um cílio. Fêmur anterior nas faces dorsal, posterodorsal e posteroventral com uma fileira de cerdas. Tíbia anterior na face anterodorsal, posterodorsal e posteroventral com uma cerda apical. Unhas e pulvilos pequenos. Fêmur médio na face posteroventral com uma série de cerdas na metade basal; faces dorsal, posterodorsal, posterior, posteroventral, ventral, anteroventral, anterior, anterodorsal com uma cerda apical. Tarsos, unhas e pulvilos como na 
perna anterior. Fêmur posterior na face dorsal com uma série de cerdas; face anterodorsal com uma série de 9-10 cerdas sub-basais. Face anteroventral com uma série sendo as duas apicais mais fortes. Face ventral com uma série de cerdas até a metade basal. Faces dorsal e anterodorsal com uma cerda pré-apical. Tíbia posterior na face anterodorsal com uma cerda mediana, uma pré-apical; face anteroventral com uma cerda mediana e uma apical forte; face dorsal com uma cerda pré-apical. Tarsos, unhas e pulvilos como nas pernas anteriores.

Abdome. Primeiro esternito nu. Quinto esternito piloso com reentrância mediana côncava alargada e duas pequenas projeções próximas à placa lateralmente (Fig. 1). Cercos pilosos com a base e braços laterais arrendondados (Figs 2-3). Hipândrio com os braços longos quase atingindo o ápice do edeago (Figs 5, 8).

Fêmea. Comprimento total $6 \mathrm{~mm}$.

Difere do macho pelos seguntes caracteres: olhos afastados por um espaço que mede ao nível do ocelo anterior cerca de 2,7 vezes a largura do terceiro artículo antenal. Cerdas frontais em número de nove pares convergentes, com o último par reclinado. Cerdas verticais externas que são divergentes. Ovipositor telescopado com inserção de pêlos enfileirados no oitavo segmento. Placa cercal triangulóide e pilosa. Espermatecas piriformes em número de três.

Material examinado. Brasil, Mato Grosso do Sul: Dourados, holótipo macho, dois parátipos machos, um parátipo fêmea, III-1974, M. Alvarenga \& O. Roppa leg.; Goiás: Jataí, um parátipo fêmea, XII-1972, F.M. Oliveira leg..

Comentários. Espécie originária do domínio do cerrado, facilmente distinta das demais espécies pela coloração amarelo dourada.

\section{Neomuscina mimosa, sp.n.}

Figs $4,9,10$

Coloração geral castanho amarelado. Antenas, palpos, genas e pós-pronoto amarelos. Arista na base amarela, seguindo castanha logo após. Cílios frontais, genais, ocelares castanho escuros. Tórax castanho amarelado com alguma pruinosidade cinzenta, visto à certa luz. Abdome castanho escurecendo para o ápice. Caliptras brancas amareladas, balacins amarelos. Asas hialinas com nervuras no ápice e transversais castanhas.

Macho. Comprimento total $5 \mathrm{~mm}$.

Cabeça. Olhos nus com facetas antero-internas alargadas sendo a largura ao nível do ocelo anterior subigual à largura do terceiro artículo antenal. Cerdas frontais em número de 12 pares convergentes, o primeiro par anterior mais forte que os demais. Cerdas verticais internas pequenas divergentes e mais fortes que as verticais externas. Antenas longas quase atingindo o epístoma e inseridos aproximadamente ao nível da metade dos olhos. Arista plumosa. Carena parafacial espaçadamente ciliada. Parafaciália subigual à espessura do terceiro artículo antenal no ápice. Vibrissas robustas e inseridas na margem oral. Epístoma não saliente. Palpos falciformes.

Tórax. Cerdas dorsocentrais $2+4$. Cerdas acrosticais $0+1$; três cerdas 

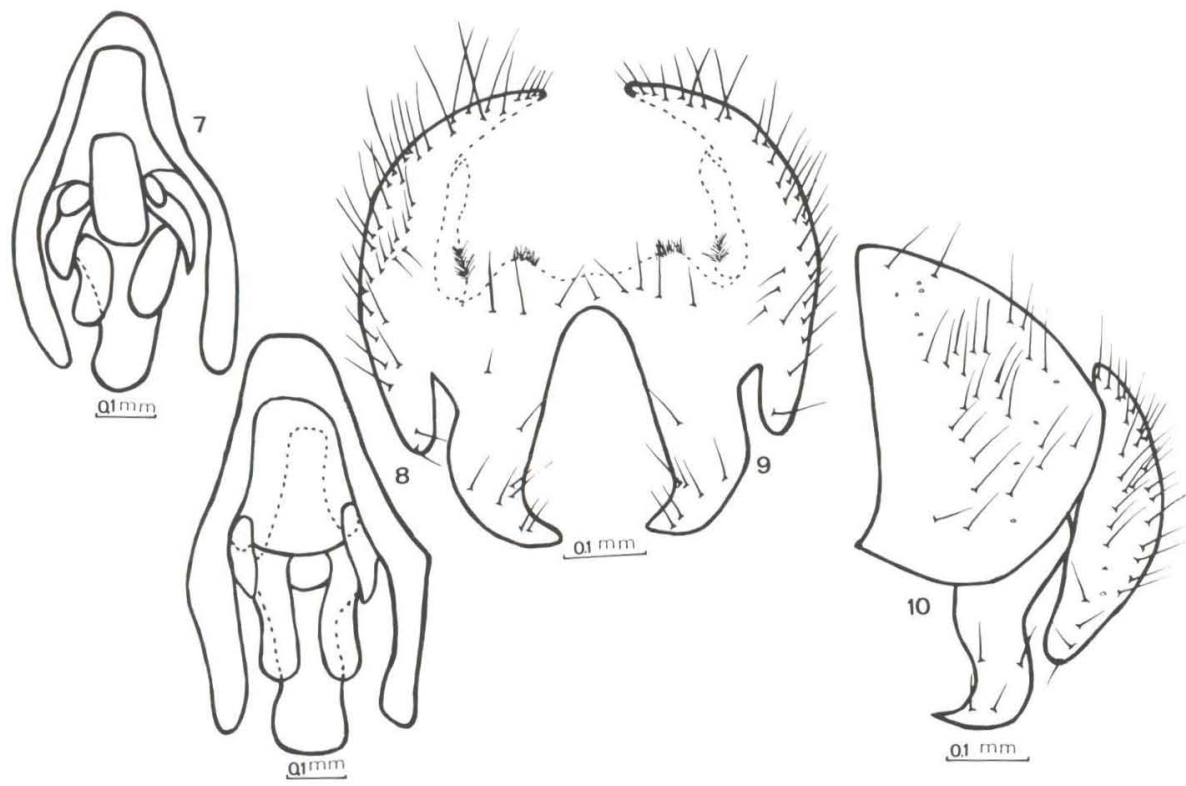

Figs 7-10. (7) Neomuscina paramediana, sp.n., pênis e anexos, vista dorsal; (8) $N$. douradensis, sp.n., pênis e anexos, vista dorsal; (9-10) placa cercal de N. mimosa, sp.n., (9) vista dorsal e (10) vista lateral.

umerais; uma pós-pronotal; uma pré-sutural; uma pré-alar pequena; duas supraalares; duas pós-supra-alares; duas notopleurais; duas pós-alares; duas intraalares. Anepisterno com uma série de oito cerdas fortes. Cerdas catepisternais 1:2; espiráculo posterior com pequena cerda na base. Escutelo com uma par de cerdas marginais, um par basal, um par discal e um par apical forte. Cílios escutelares não atingindo a superfície ventral do escutelo. Espiráculo com abertura reniforme. Caliptra torácica medindo 1,5 vezes a alar. Asa com $\mathrm{M}_{1+2}$ curva em direção ao ápice. $\mathrm{R}_{1}$ com uma cerda no nódulo na face ventral. Fêmur anterior nas faces dorsal, posterodorsal e posteroventral com uma fileira de cerdas. Tíbia na face anterodorsal com uma cerda mediana pequena; faces dorsal, posterodorsal, anterodorsal e posteroventral com uma cerda apical. Unhas e pulvilos pequenos. Fêmur médio na face ventral com seis cerdas até a metade basal; faces dorsal, posterodorsal e posterior com uma cerda apical. Face posteroventral com uma série de cerdas fortes na metade basal. Tíbia média na face posterodorsal com duas cerdas medianas; faces dorsal, posterodorsal, posterior, posteroventral, ventral e anteroventral com uma cerda apical. Tarsos, unhas e pulvilos como na perna anterior. Fêmur posterior na face ventral com três cerdas longas e finas espaçadas até a metade basal; face anteroventral com uma fileira de oito cerdas, sendo as três próximas ao ápice maiores. Faces dorsal, anterodorsal e anterior com uma cerda basal fina. Tíbia posterior na face ventral com duas cerdas medianas; face anterior com uma cerda forte mediana; faces ventral, anterior, anterodorsal e dorsal com uma cerda apical. Tarsos, unhas e pulvilos como nas pernas anteriores. 
Abdome. Primeiro esternito nu. Quinto esternito piloso com reentrâncias bastante côncavas medianamente e duas projeções digitiformes nos bordos da placa (Fig. 4). Cercos com a base arredondada e ápices afilados e pilosos (Figs 9-10).

Fêmea. Comprimento total $6 \mathrm{~mm}$.

Difere dos machos pelos seguintes caracteres: olhos afastados por um espaço que mede ao nível do ocelo anterior cerca de três vezes a largura do terceiro artículo antenal. Cerdas frontais em número de nove pares convergentes, os três pares anteriores mais fortes que os dois posteriores. Cerdas ocelares tão fortes quanto os pares maiores de cerdas frontais. Cerdas verticais internas convergentes e semelhantes às verticais externas que são divergentes. Ovipositor telescopado. Placa cercal pouco desenvolvida e cercos pilosos. Espermatecas em número de três.

Material examinado. Brasil, Goiás: Goianésia, holótipo macho, dois parátipos machos e dois parátipos fêmeas, 06-XI-1969, H. Ebert leg..

Comentários. Esta espécie é originária do domínio do cerrado e pela chave de SNYDER (1954: 425) é próxima de Neomuscina transporta Snyder, diferindo no número de cerdas intra-alares nos machos e fêmeas. SNYDER (1954) talvez por engano, assinalou o material de $N$. transporta como oriundo da África.

\section{Neomuscina paramediana, sp.n.}

Figs 6-7, 11-12

Coloração geral castanho amarelado. Antenas, palpos e parafaciália amarelas. Arista com a base amarela e ápice castanho. Cílios frontais, genais, ocelares castanho escuros. Fronte escurecida com polinosidade acinzentada, vista à certa luz, na sua maior parte inferior próximo à antena amarela. Tórax castanho com polinosidade acinzentada com quatro listras torácicas vista à certa luz. Escutelo com a metade apical amarela. Abdome com manchas castanhas e polinosidade cinzenta vista à certa luz. Caliptras e balancins branco amarelados. Asas hialinas com nervuras castanhas.

Macho. Comprimento total $6 \mathrm{~mm}$.

Cabeça. Olhos nus com facetas antero-internas alargadas sendo a largura ao nível do ocelo anterior subigual à largura do terceiro artículo antenal. Cerdas frontais em número de 11 pares convergentes, os anteriores reclinados. Cerdas verticais externas menores que as internas e divergentes. Antenas longas não atingindo o epístoma e inseridos ao nível da metade dos olhos. Arista plumosa. Carena parafacial espaçadamente ciliada. Parafaciália com a largura do terceiro artículo antenal. Vibrissas robustas inseridas na margem oral. Epístoma não saliente. Palpos falciformes.

Tórax. Cerdas dorsocentrais $2+4$. Cerdas acrosticais $0+1$; três cerdas umerais; uma cerda pós-pronotal; uma pré-sutural; uma pré-alar; uma pós-alar; duas supra-alares; duas pós-alares; duas intra-alares; duas notopleurais; anapisterno com oito cerdas sendo quatro fortes e quatro longas e finas. Cerdas catepisternais 1:2. Escutelo com dois pares de cerdas apicais. Cílios escutelares 

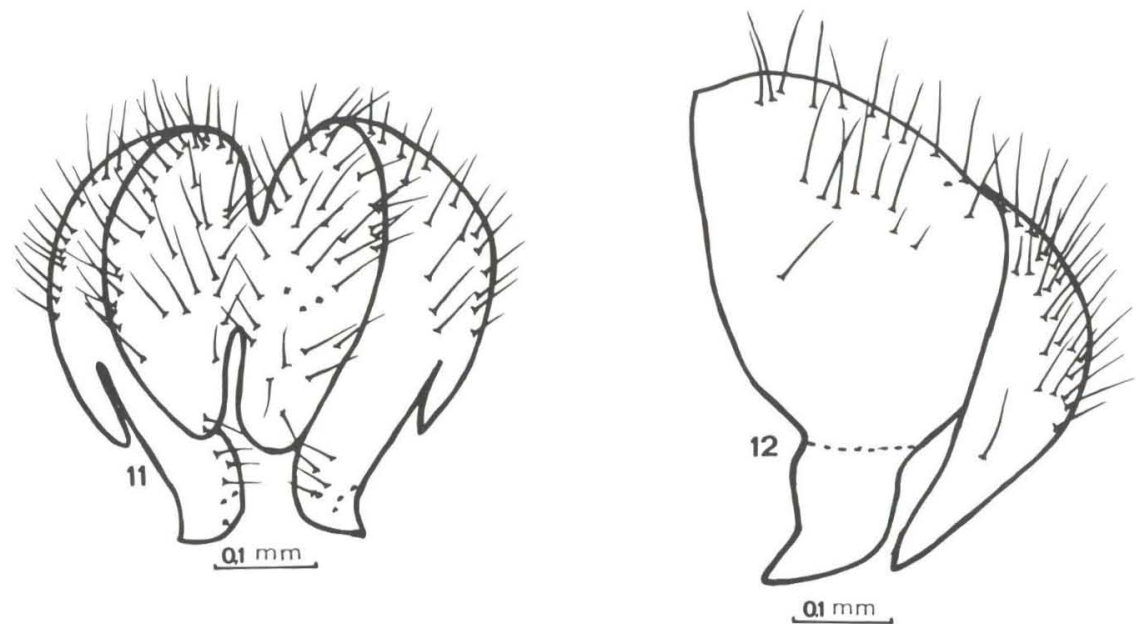

Figs 11-12. Placa cercal de Neomuscina paramediana, sp.n.. (11) Vista dorsal; (12) vista lateral.

não atingindo a margem ventral do escutelo. Espiráculo torácico com abertura reniforme. Caliptra torácica glossiforme e medindo 1,5 vezes a alar. Asas com $\mathrm{M}_{1+2}$ curva em direção ao ápice; face dorsal do nódulo da $\mathrm{R}_{1}$ com uma cerda e face ventral com uma fileira de cerdas. Fêmur anterior nas faces dorsal, posterodorsal e posteroventral com uma fileira de cerdas. Tíbia anterior nas faces dorsal, posterodorsal, posteroventral e anterodorsal com uma cerda apical e na face anterodorsal com uma cerda mediana. Unhas e pulvilos normais. Fêmur médio nas faces dorsal, posterodorsal e posterior com uma cerda pré-apical e na face ventral com seis cerdas na metade basal mais fortes que as anteriores. Tíbia média na face posterodorsal com duas cerdas submedianas espaçadas e uma quase posterior. Em todas as faces com uma cerda apical. Tarsos, unhas e pulvilos como na perna anterior. Fêmur posterior na face anteroventral com uma fileira de cerdas, sendo as duas medianas mais robustas próximas ao ápice; face posterodorsal com uma cerda pré-apical; face dorsal e anterodorsal com uma fileira de cerdas. Tíbia posterior na face anterodorsal e anteroventral com uma e duas cerdas medianas e uma na metade apical; face anteroventral com uma cerda apical. Tarsos, unhas e pulvilos como nas pernas anteriores.

Abdome. Primeiro esternito ciliado. Quinto esternito piloso e medianamente reto com duas projeções digitiformes nos bordos da placa (Fig. 6). Cercos pilosos e afilados com separação entre eles pouco nítida (Figs 11-12). Hipândrio longo quase atingindo o ápice do edeago; pré-gonitos pouco afilados e semelhantes tanto no comprimento quanto na forma dos pós-gonitos. Edeago estendendo-se além dos braços do hipândrio (Fig. 7).

Fêmea. Comprimento total $7 \mathrm{~mm}$.

Difere do macho pelos seguintes caracteres: olhos afastados por um espaço 
medindo ao nível do ocelo anterior cerca de 5,6 vezes a largura do terceiro artículo antenal. Cerdas frontais em número de oito pares convergentes, com os dois pares superiores reclinados. Cerdas ocelares maiores que quaisquer pares frontais. Cerdas verticais internas divergentes menores que o par de verticais externas, estas convergentes. Ovipositor telescopado com cerdas demarcando a separação de cada segmento. Placa cercal afilada e pilosa. Cercos pouco desenvolvidos. Espermatecas em número de três.

Material examinado: BrasiL, Goiás: Goianésia, holótipo macho, 16 parátipos machos, 23 parátipos fêmeas, 06-IX-1969, H. Ebert leg.; Jataí, dois parátipos machos, XII-1972, Alvarenga leg.; Mato Grosso do Sul: Salobra, um parátipo fêmea, Com. I.O.C. leg.; Rio de Janeiro: Rio de Janeiro (Grajau), um parátipo macho, 08-XII-1940, Lopes \& Oliveira leg.; Angra dos Reis, dois parátipos machos, um parátipo fêmea, 12-XII-1972, H.S. Lopes leg.; São Paulo: Araçatuba (Rio Jacarecatinga), um parátipo fêmea, X-1961, Lane \& Rabello leg.; Eng. Lefèvre, um parátipo fềmea, 01-XI-1937, Lopes \& Oliveira leg.; Rio Grande do Sul: São Francisco de Paula, um parátipo fêmea, I-1959.

Comentários. A espécie é originária do domínio do cerrado, caatinga, Mata Atlântica e mata de araucária. É próxima de Neomuscina mediana Snyder, 1949 , diferindo pela asa imaculada, meron nu acima da coxa III, fêmures médio e posterior não infuscados. Aproxima-se também de N. schadei Snyder, 1949, diferindo pela coloração e patas na quetotaxia.

\section{REFERÊNCIAS BIBLIOGRÁFICAS}

EMdEN, F.I. VAN. 1951. Muscidae. C-Scathophaginae, Anthomyinae, Lispinae, Fanniinae and Phaoniinae. Ruwenzori Expedition 1934-1935 British Museum, London, 2 (6): 325-710.

Pont, A.C. 1972. A Catalogue of the Diptera of the Americas South of the United States. Mus. Zool. Univ. S. Paulo 97: 1-111.

SNyder, F.M. 1949. Revision of Neomuscina Townsend, 1919. Am. Mus. Nov. 1404: $1-39$.

1954. A revision of Cyrtoneurina Giglio-Tos, 1893 with notes on related genera (Diptera-Muscidae). Bull. Am. Mus. Nat. Hist. 103 (6) : 417-464.

Townsend, C.H.T. 1919. New genera and species of muscoid flies. Proc. U.S. Nat. Mus. 56: 541-592. 